CONF- $960706--13$

\title{
Experimental Determination of Residual Stress by Neutron Diffraction in a Boiling Water Reactor Core Shroud
}

\author{
Andrew Payzant, Stephen Spooner, Xiaojing Zhu, and Camden R. Hubbard \\ Oak Ridge National Laboratory \\ PO Box 2008, Oak Ridge, TN, 37831-6064 \\ Stan T. Rosinski * \\ Sandia National Laboratory \\ Albuquerque, NM, 87185-0741 \\ John Dowicki \\ U.S. Department of Energy \\ Washington, DC
}

\begin{abstract}
$\underline{\text { Abstract }}$
Residual strains in a $51 \mathrm{~mm}$ ( 2 -inch) thick $304 \mathrm{~L}$ stainless steel plate have been measured by neutron diffraction and interpreted in terms of residual stress. The plate, measuring $(300 \mathrm{~mm})^{2}$ in area, was removed from a $6 \mathrm{~m}(20-\mathrm{ft}$.) diameter unirradiated boiling water reactor core shroud, and included a multiple-pass horizontal weld which joined two of the cylindrical shells which comprise the core shroud. Residual stress mapping was undertaken in the heat affected zone, concentrating on the outside half of the plate thickness. Variations in residual stresses with location appeared consistent with trends expected from finite element calculations, considering that a large fraction of the residual hoop stress was released upon removal of the plate from the core shroud cylinder.

\section{MASTER}

* present address: Electric Power Research Institute, 1300 Harris Blvd., Charlotte, NC, 28262

"The submitted manuscript has been authored by a contractor of the U.S. government under contract NO. DE-ACO5. 960R22464. Accordingly, the U.S. Govemment retains a nonexclusive, royalty-free license to publish or reproduce the




\section{DISCLAIMER}

Portions of this document may be illegible in electronic image products. Images are produced from the best available original document. 


\section{INTRODUCTION}

In June 1994, the nuclear power industry formed the Boiling Water Reactor Vessel and Internals Project (BWRVIP) to generically address integrity issues arising from service-related degradation of reactor pressure vessel (RPV) and RPV internal components. Specific near-term goals for the BWRVIP are to address core shroud stress corrosion cracking issues such as methodologies for reliable crack growth predictions. Reliable predictions are critical if a utility is to optimize its maintenance activities and demonstrate continued integrity of affected components. The DOE Office of Nuclear Energy, recognizing the potential impact on a third of the nuclear reactors operating in the United States, is presently supporting the BWRVIP objectives through efforts coordinated at Sandia National Laboratory.

Experimental measurement of residual stresses is fundamental to the prediction of inservice stress corrosion crack growth in nuclear reactor components such as the reactor core shroud. Welding fabrication residual stresses are the main loads on the material in an otherwise unloaded structure. Although stress measurement by X-ray diffraction is a well established technique $(1,2)$, it is limited to near-surface stresses. Neutron diffraction permits non-destructive evaluation of lattice strain within the bulk of large specimens because neutron radiation is much more deeply penetrating (3). Application of this method to mapping residual stress in welded thick stainless steel plates has been demonstrated $(4,5)$. The present project utilized neutron diffraction techniques to determine fabrication residual stresses in sections cut from an unirradiated 304L stainless steel core shroud. This data was used to assist in evaluating reliable crack growth prediction methodologies under development by the BWRVIP. In this project, three components of residual stress have been measured at locations within the weld heat affected zone of a sample containing a horizontal weld.

\section{EXPERIMENTAL PROCEEDURES}

\section{(1) Specimen}

The boiling water reactor core shroud was fabricated by Bingham Willamette, Ltd., by welding pre-formed steel plates into cylinders and then welding the cylinders together to form the final shroud structure. The material under investigation is the base metal in the heat affected zone of the final horizontal weld. The weld is a multiple-pass double V-groove (offset) weld made by the gas tungsten arc process. A $915 \mathrm{~mm}(3-\mathrm{ft}$.) diameter plug was cut from the shroud so as to 
contain both a vertical weld and horizontal weld and samples were removed and examined at several laboratories by a variety of techniques. In this study, a $305 \mathrm{~mm}$ square plate was cut from the plug so that the horizontal weld was centered in the plate, as shown in Figure 2 . The base metal was 304L stainless steel and the filler metal was 308L stainless steel.

The residual stress state in the welded plate arises not only from the thermal expansion effects of welding but also from the pre-welding fabrication and post-welding treatment. The process of removing the welded specimen from the shroud was expected to provide a significant degree of stress relaxation, as demonstrated by the increase in the radius of curvature of the plug specimen to $2.86 \mathrm{~m}(9.396 \mathrm{ft})$, compared to $2.65 \mathrm{~m}(8.705 \mathrm{ft})$ prior to removal. It should be assumed that additional stress relaxation occurred as the $305 \mathrm{~mm}$ square plate was removed from the plug, although this was not verified experimentally. This study of the welded plate excluded the fusion zone and therefore the material examined is single-phase austenite. The general configuration of the specimen is illustrated in Figure 2.

\section{(2) Neutron Diffractometer}

Neutron scattering experiments were carried out on the HB-2 spectrometer at the High Flux Isotope Reactor (HFIR) of the Oak Ridge National Laboratory. The incident neutron beam was made monochromatic by diffraction from the (11.0) planes of a beryllium single crystal. The monochromator drum was set at $84^{\circ} 2 \theta_{\mathrm{m}}$ and the wavelength was determined to be $0.153 \mathrm{~nm}$ from analysis of a nickel powder standard. The nominal Bragg diffraction angle for the $\alpha$-Fe 311 plane is $89.6^{\circ} 2 \theta$. Narrow incident and receiving slits define the gauge volume within the specimen, as shown schematically in Fig.1. In this experiment, neutron beam collimation between the monochromating crystal and the sample was defined by a $12.7 \mathrm{~mm}$ wide insert in the monochromator drum shield and a $5 \mathrm{~mm}$ wide incident beam aperture. The scattered beam collimation was defined by a $5 \mathrm{~mm}$ scattered beam aperture and an ORELA position-sensitive detector located at $800 \mathrm{~mm}$ from the sample. The detector active area is $100 \mathrm{~mm}$ long by $40 \mathrm{~mm}$ high, permitting collection of diffraction data over an approximately $6^{\circ} 2 \theta$ range. The detector output, which is proportional to location along the $100 \mathrm{~mm}$ length, is fed to a 512 channel multichannel analyser. The angle-displacement relationship for the position-sensitive detector was carefully calibrated by measurements of controlled displacements of a sharp Bragg peak. The incident and scattering apertures were located approximately $75 \mathrm{~mm}$ from the diffractometer axis in order to accommodate the translations made during the course of mapping measurements. 
The precise location of the diffracting volume within the specimen was controlled by appropriate translation and/or rotation of the sample. In the measurement of the horizontal weld (H5), the radial and axial components of residual strain were measured with the weld oriented vertically. The gauge volume was defined by incident and scattered beam apertures made of cadmium which pass beams $5 \mathrm{~mm}$ wide and $10 \mathrm{~mm}$ tall. In the measurement of hoop components the weld was oriented horizontally and the gauge volume was defined by apertures which pass beams $5 \mathrm{~mm}$ wide and $5 \mathrm{~mm}$ tall, the orientation of which is shown in the photograph (Fig.3) of the experimental layout. The coordinates of the sampling positions, given in Table 1, were referenced to the mid-thickness of the plate and to a displacement from the top edge of the fusion zone shown in Fig.4, which shows the macro-etched surface of a sample that was cut adjacent to the $305 \mathrm{~mm}$ plate. The plate was clamped and mounted on an X-Y translation table. The location of the external surface on the outside diameter of the plate was verified by making an intensity scan and fitting the intensity changes as a function of location using a non-linear fit, as described by Brand (6). Axial and radial strain components were measured with the weld aligned vertically, using the $\mathrm{X}$-Y translation table to locate the diffracting gauge volume in the correct position. The plate was remounted with the weldline horizontal for measurement of the hoop components of residual strain, which required vertical displacements of the sample. This was accomplished using shims placed under the sample in order to give the needed displacements of the diffracting volume from the weld edge. These displacements were checked with an aligned optical telescope to an estimated accuracy of $\pm 0.2 \mathrm{~mm}$.

\section{(3) Measurement of Strain}

Macro-residual strain can be determined from the change in lattice d-spacing of diffracting grains in a polycrystalline diffraction peak from that of a strain-free reference material. The strain is an average of the strains in the large number of grains within the sampling volume that are oriented for the particular scattering geometry defined by the incident and scattered beams. The Bragg angle determined in the scattering measurement yields a lattice d-spacing

$$
d_{h k l}=\frac{\lambda}{2 \sin \theta_{h k l}}
$$

where $\lambda$ is the wavelength of the neutrons and $\theta_{\mathrm{hkl}}$ is one-half the scattering angle for a diffraction peak corresponding to the crystallographic Miller indices $h, k, l$. The direction of the measured strain bisects the incident and scattered beams. This residual strain component is calculated from the shift in the $d$-spacing relative to a stress-free $d$-spacing by 


$$
\varepsilon=\frac{d_{h k l}-d_{h k l}^{o}}{d_{h k l}^{o}}
$$

where $d_{h k l}^{o}$ is the d-spacing of the stress-free reference. Substitution of Bragg's law into this strain equation gives, equivalently,

$$
\mathcal{E}=\frac{\sin \theta_{h k l}^{o}}{\sin \theta_{h k l}}-1
$$

which shows how a shift in the Bragg diffraction angle is used to calculate the lattice strains. The $2 \theta$ value is obtained by fitting a Gaussian function and linear background to the measured peak intensity. The $2 \theta_{\text {hkl }}$ was determined typcally to an accuracy of $\pm 0.001^{\circ}$. For $2 \theta$ values near $90^{\circ}$, this yields a typical precision in strain of a few parts in 10,000. The strain determinations are based on Bragg peak shifts relative to a reference Bragg peak position measured with the same fixed position-sensitive proportional counter. The stability of the Bragg peak measurements in the course of a measurement campaign was monitored by repeated measurements of a relative reference point (in the sample itself) or a reference bar (attached to the sample). This would potentially substitute for an absolute reference scattering angle measurement of $2 \theta_{\mathrm{hkl}}$, so long as the reference point is known to be stress-free.

A Monte Carlo program, ARTISHIFT, (7) was used to model the experimental conditions to check for shifts in the measured Bragg angle due to the comparitively large gauge volume. This model indicated that, for the transmission geometry utilized for the hoop and axial measurements, the peak shift is below the statistical error of the peak, that is $|\Delta 2 \theta| \leq 0.001^{\circ}$. For the reflection geometry utilized for the radial and reference bar measurements, the peak shift was found to be a constant of magnitude $\Delta 2 \theta=0.010^{\circ}$, irrespective of location within the sample. This peak shift is due to the relatively large gauge volume. In the reflection geometry, neutrons diffracting from one side of the gauge volume have sufficient differences in pathlength through the steel compared to neutrons diffracting from the other side. Differences in absorption cause the neutron distribution at the detector to shift to higher angles. For the transmission geometry, the path differences are symmetric, so no shift is observed in the diffracted neutron distribution at the detector.

An accurate Bragg peak measurement from a stress-free reference sample is required for accurate residual strain determination. In previous investigations of 300-series stainless steel welds $(4,8,9)$ it proved sufficient to carefully remove a small reference piece of base metal from the 
edge of the welded plate at a location far from the fusion zone. The removal of the mechanical constraints of the surrounding material by cutting is usually enough to reduce any remaining residual strain to a value below the limits of detectability. In this investigation we have used a thin slab of material cut adjacent to the H5 weld piece, from which an $8 \mathrm{~mm} \times 8 \mathrm{~mm} \times 50 \mathrm{~mm}$ pillar was removed from a location more than 6 inches from the fusion zone, which thus represents the metallurgical condition of the base metal.

Concerning composition effects, it had been observed in prior studies of 300 -series stainless steel welds $(4,8,9)$ that the composition of the heat affected zone (HAZ) is not measurably different from the base metal. The fraction of delta (bcc) iron is below the limit of neutron diffraction detectability (less than $2 \%$ ) and a micro-fluorescence scan for iron, nickel and chromium from the HAZ to the base metal showed no systematic variation of composition arising from the transient annealing in the HAZ. The changes in d-spacing between different parts of the HAZ and the base metal therefore are regarded as being smaller than the limits of detectability in the residual strain mapping experiment.

The residual strains were measured in three mutually perpendicular directions which would be the expected principal axes within the HAZ and base metal. Since the plate was cut from a large cylinder, the assumption that the measured directions correspond to the principal axis may only be an approximation, in which case the stresses operating on the sample in the measured directions will not be simple principal stresses but will also include shear stresses. The calculation of the residual stresses from the measured strains is accurate, but it cannot be assumed that these are necessarily the principal stresses. Hole drilling measurements on the core shroud, undertaken at Sandia National Laboratory, had indicated that the principal axis were in fact tilted away from the nominal symmetry axes used for the scattering measurements. However, as noted above, cutting the plates from the shroud modifies the residual stress state, and so the hole drilling results and the neutron scattering results are not expected to be equivalent.

The residual stress components are calculated in terms of the strain components by the following relation:

$$
\sigma_{x}=\frac{E}{1+v}\left(\varepsilon_{x}+\frac{v}{1-2 v}\left(\varepsilon_{x}+\varepsilon_{y}+\varepsilon_{z}\right)\right)
$$

in which $E$ and $v$ are the appropriate values of Young's modulus and Poisson's ratio, respectively, for the crystallographic direction, $h k l$. The other stress components follow by permuting the indices of the orthogonal axes. The effective value of the elastic modulus depends on the direction 
in a face centered cubic crystal, for which the softest direction is the [001] and the stiffest is the [111]. The [311] direction was used in this study, which has a modulus that is intermediate between these extremes, and is closer to the bulk Young's modulus of $190 \mathrm{GPa}$ and Poisson's ratio of 0.29 . This set of planes has a high crystallographic multiplicity which yields good intensity, lies close enough to $90^{\circ} 2 \theta$ at the wavelength selected so that the diffracting volume is nearly cubic, and has a reduced sensitivity to variations in texture. Grain size effects were further reduced by oscillation of the plate by $\pm 1^{\circ}$ about the diffractometer axis during the collection of the scattering data.

The evaluation of the average elastic constants depends on the method of averaging elastic properties for a polycrystalline material $(1,2)$. For instance, the Voigt model assumes a constant strain distribution in all the grains, whereas the Reuss model assumes a constant stress distribution. These are, effectively, the lower and upper bounds for the average elastic constants, whereas the Kröner model gives values which are closer to experimentally determined single crystal values. The elastic constants for the 311 direction, as obtained from these different models for 304L stainless steel, are:

$\begin{array}{lll}\text { Voigt: } & \mathrm{E}=139 \mathrm{GPa} & v=0.356 \\ \text { Kröner: } & \mathrm{E}=184 \mathrm{GPa} & \mathrm{v}=0.309 \\ \text { Reuss: } & \mathrm{E}=225 \mathrm{GPa} & v=0.266\end{array}$

Despite the large differences in constants as estimated by these models, it was found in this case that the calculated stresses were not particularly dependent on the model selected, and only results using the elastic constants from the Kröner model will be described herein.

\section{RESULTS AND DISCUSSION}

a) Raw data

Preliminary experiments were made to evaluate the attenuation of the neutron beam by the sample, and assess the impact on data collection time and strategy, given that past experience had indicated that an approximately $25 \mathrm{~mm}$ thickness of stainless steel was the practical limit to residual stress mapping by neutron diffraction. On the basis of the preliminary data, it was determined that large beam apertures ( $5 \mathrm{~mm}$ ) and long counting times (up to 6 hours per location) enabled recording of Bragg peaks of sufficient intensity for strain mapping. A sequence of eight experimental runs were undertaken over the remaining available neutron beam time (about 7 days), each run including 
many data points at the $\mathrm{x}$ and $\mathrm{y}$ coordinates indicated in Figure 4, at three orthogonal orientations (i.e., hoop, radial, or axial). In all, some twenty four locations were examined near the fusion zone side of the heat affected zone. In some cases only one or two of the three strain components were measured for reasons of inadequate intensity or because of limited time.

\section{b) 2-theta corrections}

Experimental runs \#1 through \#5 each included measurements of a reference point located near the cut end of the plate in the hoop orientation. This point near the surface was selected both for convenience, and because it was assumed that, at this position, the residual hoop stress would be largely relieved due to removal of mechanical constraints. Between the third and fourth set of experiments the positions of the incident and receiving slits were adjusted to improve their alignment. The 311 peak position of the relative reference position was subsequently found to shift from $89.474^{\circ} 2 \theta$ to $89.451^{\circ} 2 \theta$. Consequently, the peak positions recorded in run \#4 and \#5 were corrected by adding a constant $0.023^{\circ}(2 \theta)$ to be comparable to the earlier data files. Experimental runs \#6 through \#8 each included measurements of a reference point located near the outer diameter of the plate in the radial orientation. This point was selected for convenience due to limitations in the available sample traverse, but enabled the data sets to be corrected relative to the previous data by comparison with the essentially equivalent radial $2 \theta$ value obtained at $y=5 \mathrm{~mm}$ nearest the outer diameter. The 311 peak position at this point was found to have shifted from $89.531^{\circ}$ to $89.546^{\circ}$ in $2 \theta$. Some peak shift was once again expected, due to a second adjustment of the incident and receiving slit positions between runs \#5 and \#6, and consequently the peak

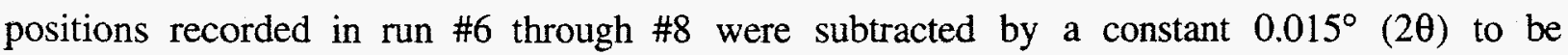
comparable to the earlier data files.

As a further correction, all of the radial data peak positions, once corrected by the relative reference shifts, were also corrected for asymetric neutron attenuation by subtracting $0.010^{\circ}$, based on the results of the Monte Carlo simulation of the reflection geometry, as previously discussed in the Experimental Procedures.

c) strain and stress calculations

The 311 peak position in the small reference sample cut from the strip supplied by the customer was recorded (as part of the eighth and final experiment) at $2 \theta=89.497 \pm 0.003^{\circ}$, which was corrected to $89.482 \pm 0.003^{\circ}$ based on the relative reference correction, and then to 89.472 $\pm 0.003^{\circ}$ after applying the $\Delta 2 \theta$ shift for the reflection geometry, as described previously. This 
corrected value was used as the stress-free $2 \theta$ angle for all calculations of strain in the H5 sample, on the assumption that the small physical dimensions of this sample would permit significant stress-relief to occur through the removal of the material restraints. The correspondence between the corrected $2 \theta$ value of the Stress Free Reference at $89.472 \pm 0.003^{\circ}$ and the corrected $2 \theta$ value of the relative reference position measured in runs \#1 through \#5 at $89.464 \pm 0.002^{\circ}$ implies that the first relative reference point was nearly stress free in the hoop direction, as expected.

The count rates in the axial and hoop directions were very low as a result of the long $(75 \mathrm{~mm})$ pathlength for neutrons in the steel plate, whereas the intensity in the radial direction was a strong function of the depth into the sample, as expected. The FWHM of the Bragg peaks do not change much with position in any of the three orientations. The strains were determined as in Eqn.3, and multiplied by $10^{4}$ to obtain values on the order of ten. Stresses were calculated from the strain values, as in Eqn.4, using the Kröner elastic constants for the 311 direction in 304L stainless steel. These calculated strains and stresses are given in Table I, in normal (i.e., nonitalicized) type.

d) Estimation of additional data points

Time constraints and/or poor counting statistics prevented measurement of several important strain components, as indicated in Table I. An estimation of the missing values was attempted to fill in the data tables. The three missing axial strain values for $y=5 \mathrm{~mm}$ were assumed to be similar to the recorded values for $y=10 \mathrm{~mm}$ at the same depth, $x$. The estimated values are taken from the fitted curve through the corresponding points (see Figs.5-7) The two missing radial strain values for $y=5 \mathrm{~mm}$ were interpolated from the bounding measured data. In this way a more complete strain map at $y=5 \mathrm{~mm}$ was obtained. The "estimated" strain and stress data are included in Table I, in the shaded fields. Some validation of this procedure comes from the observation that the calculated radial stresses are near zero as expected, and that the axial stresses are compressive near the centerline as expected. The complete set of strain values are plotted (with respect to the $y$ coordinates defined in Figure 4) as Figures 5-7, and the calculated residual stresses are plotted as Figures 8-10.

e) Force balance check

Force balance requires that the integration of forces over the thickness of the material must be zero. In the H5 weld section under investigation, force balance along a line through the thickness (which was defined as the $y$-axis) is required only for the radial and axial components. 
The hoop stresses need not be balanced on such a line, as from symmetry considerations they may be balanced instead at positions offset from a given $y$-coordinate. In addition, the radial stress must extrapolate to zero at the surface (i.e., at the $\mathrm{DD}$ and $\mathrm{OD}$ ), and the remaining radial (pseudonormal) stresses are generally expected to be low in this approximately flat plate geometry. Finally, stresses are not expected to exceed the yield stress for the material, since such stress levels would result in plastic yield to relieve the stress.

The present results correspond reasonably well to the conditions stated above. The radial stresses are generally zero, within a standard deviation of the data. It is noteworthy that the nonzero radial strains arise from Poisson's ratio effects. The axial stresses near the weld are highly tensile near the ID and OD, and highly compressive near the centerline. Force balance is achieved, within about one standard deviation of the data. The hoop components near the weldline are all somewhat tensile, but this does not appear to be in violation of mechanical stability, as force balance for hoop stresses is not required along the line in question. The largest tensile stresses approach the material yield stress, but do not grossly exceed this value, which itself is difficult to define due to thermal treatment of the base metal near the weldline in the HAZ.

\section{f) Uncertainty in the Strain and Stress Determinations}

Determinations of residual stress are subject to uncertainties that in one case can be estimated quantitatively from the statisitics of Bragg peak fitting and, in the second case, the uncertainties having to do with the accurate determination of the stress-free lattice spacing which determines the reference Bragg angle. The conversion of strain to stress adds another degree of uncertainty, but with the difference that the assumption of limiting cases of elastic behavior (Voigt and Reuss) permits the bracketing of the probable range of stresses in this case to within approximately one estimated standard deviation of the data.

An error in the stress-free $2 \theta$ reference would simply shift all the strain and stress data up or down by some constant value. Such a $2 \theta$ change will have the effect of augmenting or diminishing the hydrostatic or dilational stress component of the residual stress tensor, but the distortional stress tensor, obtained by subtraction of the purely dilational stress, will remain unchanged. The reference can be evaluated by cross checking the boundary conditions and force balances on the residual stress results. In the present case, the value of the the stress component perpendicular to the external surface (the radial component) must extrapolate to zero, for example. The force balance on the radial and axial residual stress components, which is an integration of the strains along a line through the plate thickness, must also be zero. The final residual stresses 
adhere closely to these expected boundary conditions without having to invoke any strain adjustment.

The reference specimen was re-examined using a gauge volume of $3 \mathrm{~mm} \times 3 \mathrm{~mm} \times 3 \mathrm{~mm}$, smaller than the gauge volume used in the original experiments. and for which any peak shift in the reflection geometry is negligible. The reference was set up to rotate on its long axis and a series of Bragg diffraction peak measurements were made as a function of angle. Some variation in peak position with rotation angle was observed, possibly due to large grain size, texture gradients, or simply residual stresses retained from the plate itself, or from the machining and cutting processes. It may be concluded that the as-used reference strain error must be small $\left(<0.01^{\circ}\right)$, based on the diffraction data and since the results of the analyses are in reasonable agreement with force balance limits.

The "true" error bars for the present results (which are constituted by statistical, strain-tostress conversion, and stress-free d-spacing uncertainties) are estimated to be approximately twice the counting statistics error bars shown in the tables and figures, where the estimated statistical error in the calculated stresses, as represented by one standard deviation in the peak profile fitting routines, was typically $40-50 \mathrm{MPa}$ for the hoop stress, $30-40 \mathrm{MPa}$ for the axial stress, and 10-15 $\mathrm{MPa}$ for the radial stress components.

\section{SUMMARY AND CONCLUSIONS}

Residual strains in a $51 \mathrm{~mm}$ thick $304 \mathrm{~L}$ stainless steel plate have been measured by neutron diffraction and interpreted in terms of the principal residual stresses. The plate measuring $300 \mathrm{~mm}$ $\mathrm{x} 300 \mathrm{~mm}$ in area was removed from a 6.1 metre $(20-\mathrm{ft}$.) diameter power reactor core shroud and contained a multiple-pass weld which joined two of the cylindrical shells which comprised the core shroud. The residual stresses parallel to the weld line (hoop) are relatively large and tensile, the stresses at right angles to the weld and in the plate (axial) are also large and include both tensile and compressive values, and the stresses perpendicular to the plate (radial) are near zero. The largest tensile axial stress found is near yield and is located in the heat affected zone next to the fusion zone near the inner diameter. The largest tensile hoop stress found is near yield and is located in the heat affected zone next to the fusion zone near the outer diameter. These findings differ somewhat from finite element calculations carried out elsewhere, but the differences may be due to the relieving of a significant fraction of the residual hoop stresses upon removal of the plate from the core shroud cylinder. A limited degree of stress mapping was undertaken in the heat affected zone on the outside half of the plate thickness. The residual stress components adhere generally to 
the trends anticipated from finite element calculations, noting that the use of a $(5 \mathrm{~mm})^{3}$ diffracting volume will have averaged out sharp residual stress variations; thus local residual stresses could be higher than, and exhibit more variation than, the measured values.

Large tensile residual stress components were seen at the inner diameter; $311 \pm 32 \mathrm{MPa}$ axial at the inner diameter and $325 \pm 58 \mathrm{MPa}$ tensile hoop at the outer diameter very near the fusion zone, based on the use of Kröner averages for the Young's modulus and Poisson's ratio. The axial and radial stress components are very nearly in balance through the thickness. The largest throughthickness variation in residual stress was observed for the axial component, for which the stresses were tensile near the ID and OD, and compressive in the center. The radial residual stresses were within $\pm 50 \mathrm{Mpa}$ of zero with the exception of points nearest the fusion zone where larger tensile stress components were observed.

\section{Acknowledgments}

Research sponsored by the Assistant Secretary for Energy Efficiency and Renewable Energy, Office of Transportation Technologies, and the Assistant Secretary for Energy Research, Division of Materials Science, as part of the High Temperature Materials Laboratory User Program, Oak Ridge National Laboratory, managed by Lockheed Martin Energy Research Corp. for the US Department of Energy, under contract DE-AC05-96OR22464. EAP and XZ were supported in part by appointments to the ORNL Postdoctoral Research Associates Program administered jointly by ORNL and ORISE.

\section{$\underline{\text { References }}$}

1. Residual Stress Measurement by X-Ray Diffraction - SAE J784a, 2nd edition, pp.48-49, Society of Automotive Engineers, Inc., Warrendale, PA, 1971.

2. I.C. Ismail and J.B. Cohen, Residual Stress, Springer-Verlag, New York, 1987.

3. P.J. Webster, "Welding Applications of Neutron Strain Scanning", in International Trends in Welding Science and Technology [S.A. David and J.M. Vitek, eds.], pp.95-98, ASM International, Materials Park, OH, 1993.

4. J.H. Root, T.M Holden, J. Schröder, S. Spooner, C.R. Hubbard, T.A. Dodson, S.A. David, "Residual Stresses in a Multipass Ferritic Weldment", in International Trends in Welding Science and Technology [S.A. David and J.M. Vitek, eds.], pp.99-104, ASM International, Materials Park, OH, 1993. 
5. S. Spooner, J.A. Fernandez-Baca, S.A. David, C.R. Hubbard, T.M. Holden, J.H. Root, "Investigation of Residual Stresses in a Multipass Weld in 1" Stainless Steel Plate", in Proceedings of the 4th International Conference on Residual Stresses, ICRS 4, pp.12051209, Society for Experimental Mechanics, Inc., Bethel, CT, 1994.

6. P.C. Brand, Stress Measurement by Means of Neutron Diffraction, Report No. ECN-R91-006, Netherlands Energy Research Foundation ECN, Petten, The Netherlands, 1991.

7. S. Spooner and X.L. Wang, personal communication

8. S. Spooner, X.L. Wang, C.R. Hubbard, S.A. David, "Residual Stresses in a Multi-Pass Weld in an Austenitic Stainless Steel Plate Before and After Thermal Stress Relief', in Proceedings of the 4th International Conference on Residual Stresses, ICRS 4, pp.964969, Society for Experimental Mechanics, Inc., Bethel, CT, 1994.

9. M. Li, D.G. Atteridge, W.E. Anderson, C.R. Hubbard, S. Spooner, X.L. Wang, S.L. West, "An Experimental Analysis of Temperature and Stress Fields in Girth Welded 304L Stainless Steel Pipes", in Proceedings of the 4th International Conference on Trends in Welding Research, Gatlinburg, TN, in the press.

\section{DISCLAIMER}

\footnotetext{
This report was prepared as an account of work sponsored by an agency of the United States Government. Neither the United States Government nor any agency thereof, nor any of their employees, makes any warranty, express or implied, or assumes any legal liability or responsibility for the accuracy, completeness, or usefulness of any information, apparatus, product, or process disclosed, or represents that its use would not infringe privately owned rights. Reference herein to any specific commercial product, process, or service by trade name, trademark, manufacturer, or otherwise does not necessarily constitute or imply its endorsement, recommendation, or favoring by the United States Government or any agency thereof. The views and opinions of authors expressed herein do not necessarily state or reflect those of the United States Government or any agency thereof.
} 
Table I

Measured Strains, Estimated Strains, and Derived Stresses

\begin{tabular}{|c|c|c|c|c|c|c|c|c|c|c|c|c|c|}
\hline & & & & \multicolumn{3}{|c|}{ Elastic modulus (GPa) } & 184 & $\mathrm{GPa}$ & & & & & \\
\hline & & & & \multicolumn{3}{|c|}{ Poisson's ratio } & 0.309 & & & & & & \\
\hline$x$ & $y$ & \multicolumn{2}{|c|}{ hoop strain } & \multicolumn{2}{|c|}{ axial strain } & \multicolumn{2}{|c|}{ radial strain } & \multicolumn{2}{|c|}{ hoop stress } & \multicolumn{2}{|c|}{ axial stress } & \multicolumn{2}{|c|}{ radial stress } \\
\hline$(\mathrm{mm})$ & $(\mathrm{mm})$ & $(\times 10000)$ & esd & $(\times 10000)$ & esd & $(x 10000)$ & esd & $(\mathrm{MPa})$ & esd & $(\mathrm{MPa})$ & esd & $(\mathrm{MPa})$ & esd \\
\hline-21 & 10 & 6.02 & $1,4.1$ & 11.20 & 1.15 & -8.27 & 0.18 & 161.1 & 38.6 & 248.0 & 31.8 & -25.7 & 10.0 \\
\hline-17 & 10 & 1.67 & 1.50 & 5.11 & 1.06 & -5.54 & 0.78 & 37.6 & 40.9 & 86.0 & 29.6 & -63.8 & 10.1 \\
\hline-13 & 10 & 4.58 & 1.76 & -1.23 & 0.97 & .2 .82 & 0.18 & 70.5 & 48.0 & -11.3 & 27.6 & -33.5 & 10.9 \\
\hline-9 & 10 & 1.67 & 2.11 & -3.96 & 1.14 & 0.18 & 0.26 & -0.5 & 57.5 & -79.7 & 32.7 & -21.5 & 13.7 \\
\hline 0 & 10 & 2.82 & 1.76 & -6.07 & 1.58 & 0.6 & $=1$ & 9.5 & 48.6 & -115.5 & 44.0 & -21.7 & 29.4 \\
\hline 9 & 10 & 5.64 & 1.50 & -2.99 & 1.41 & -1.7 & 1 & 90.1 & 41.4 & -31.3 & 39.1 & -13.1 & 28.9 \\
\hline 13 & 10 & 5.55 & 1.68 & -0.26 & 1.32 & -4.14 & 0.18 & 91.2 & 45.8 & 9.4 & 36.7 & -45.1 & 11.4 \\
\hline 17 & 10 & 10.59 & 1.85 & 2.73 & 1.32 & -4.93 & 0.18 & 244.2 & 50.6 & 133.8 & 36.9 & 26.1 & 12.1 \\
\hline 21 & 10 & $1,1.08$ & 1.85 & 2.47 & 1.50 & -4.49 & 0.09 & 257.4 & 50.7 & 137.1 & 41.5 & 39.3 & 11.8 \\
\hline & & & & & & & & & & & & & \\
\hline-21 & 5 & 5.02 & 1.41 & 13.68 & 1.15 & -8.27 & 0.18 & 189.3 & 38.6 & 310.9 & 31.8 & 2.4 & 10.0 \\
\hline-17 & 5 & 1.67 & 1.50 & 4.85 & 1.06 & -5.54 & 0.18 & 34.6 & 40.9 & 79.3 & 29.6 & -66.8 & 10.1 \\
\hline-13 & 5 & 4.58 & 1.76 & -0.62 & 1.59 & -2.82 & 0.18 & 77.5 & 48.4 & 4.4 & 43.8 & -26.5 & 12.5 \\
\hline-9 & 5 & 1.67 & 2.11 & -2.99 & 1.14 & 0.18 & 0.26 & 10.5 & 57.5 & -55.1 & 32.7 & -10.5 & 13.7 \\
\hline 0 & 5 & 2.82 & 1.76 & $-5,10$ & 1.58 & 0.6 & 1 & 20.5 & 48.6 & -90.9 & 44.0 & -10.7 & 29.4 \\
\hline 9 & 5 & 5.64 & 1.50 & $-2,02$ & 1.41 & -1.7 & 1 & 101.1 & 41.4 & -6.7 & 39.1 & -2.1 & 28.9 \\
\hline 13 & 5 & 5.55 & 1.68 & 3.26 & 1.67 & -4.14 & 0.18 & 131.2 & 46.1 & 99.0 & 46.1 & -5.0 & 12.5 \\
\hline 17 & 5 & 10.59 & 1.85 & 2.38 & 1.32 & -4.93 & 0.18 & 240.2 & 50.6 & 124.8 & 36.9 & 22.1 & 12.1 \\
\hline 21 & 5 & 11.03 & 1.85 & 0.79 & 1.41 & -4.49 & 0.09 & 238.4 & 50.6 & 94.5 & 39.2 & 20.3 & 11.6 \\
\hline & & & & & & & & & & & & & \\
\hline 9 & 0 & 13.06 & 2.03 & -2.91 & 2.20 & -0.70 & 0.79 & 291.0 & 56.1 & 66.6 & 60.5 & 97.6 & 25.9 \\
\hline 13 & 0 & 9.53 & 1.50 & 2.64 & 1.85 & -2.20 & 0.62 & 247.2 & 41.7 & 150.5 & 50.7 & 82.4 & 20.3 \\
\hline 17 & 0 & 12.18 & 1.50 & 3.79 & 1.94 & -4.58 & 0.35 & 300.7 & 41.7 & 182.8 & 53.0 & 65.2 & 15.3 \\
\hline 21 & 0 & & & & & -3.52 & 0.18 & & & & & & \\
\hline & & & & & & & & & & & & & \\
\hline 9 & -5 & 9.17 & 2.82 & -2.82 & 1.76 & -2.73 & 0.70 & 170.2 & 77.0 & 1.6 & 49.7 & 2.9 & 25.0 \\
\hline 13 & -5 & 13.59 & 2.12 & 0.35 & 1.85 & -2.20 & 0.53 & 324.6 & 58.1 & 138.5 & 51.2 & 102.6 & 19.8 \\
\hline 17 & -5 & 10.41 & 2.12 & & & & & & & & & & \\
\hline
\end{tabular}




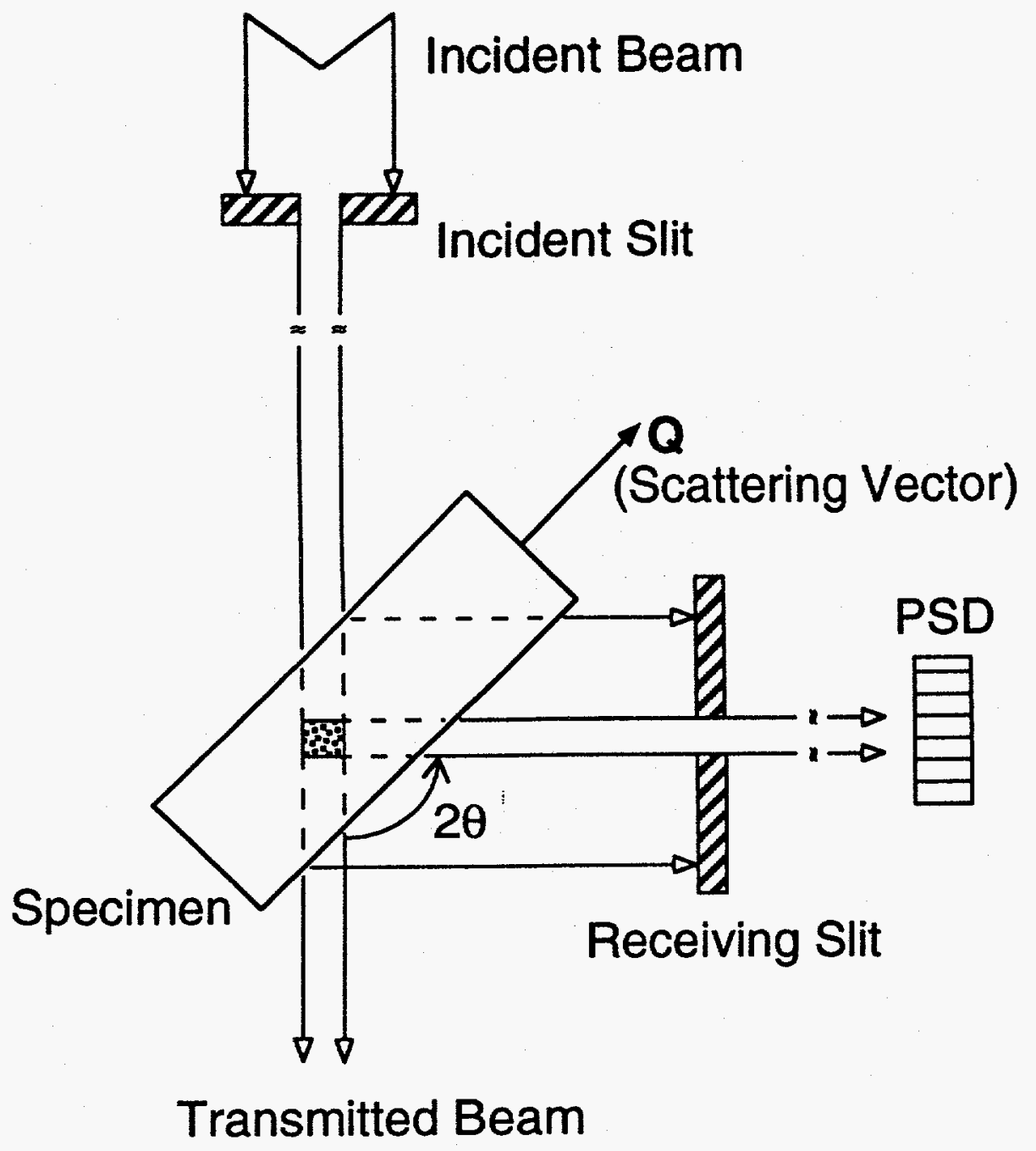

Figure 1 Schematic of the Experimental Setup 

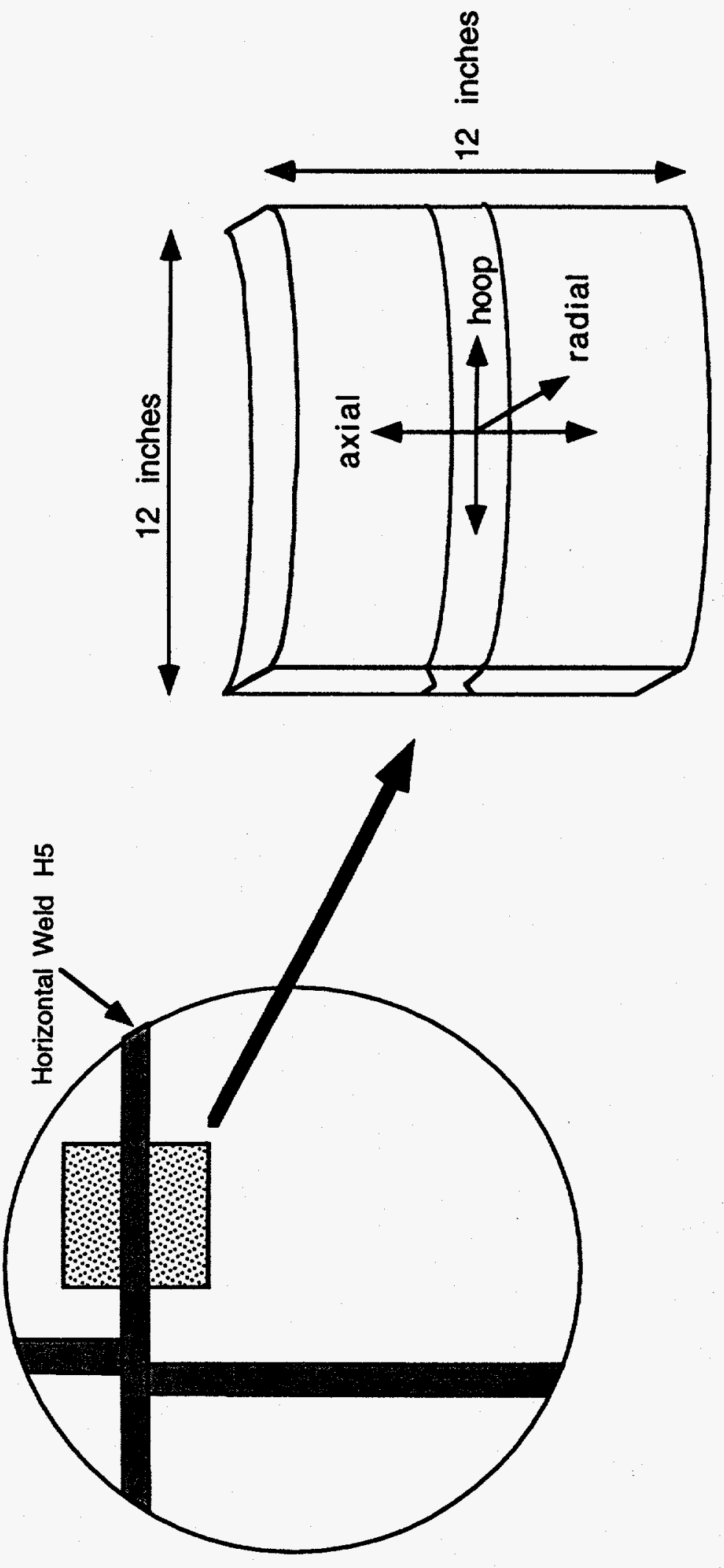

岂 


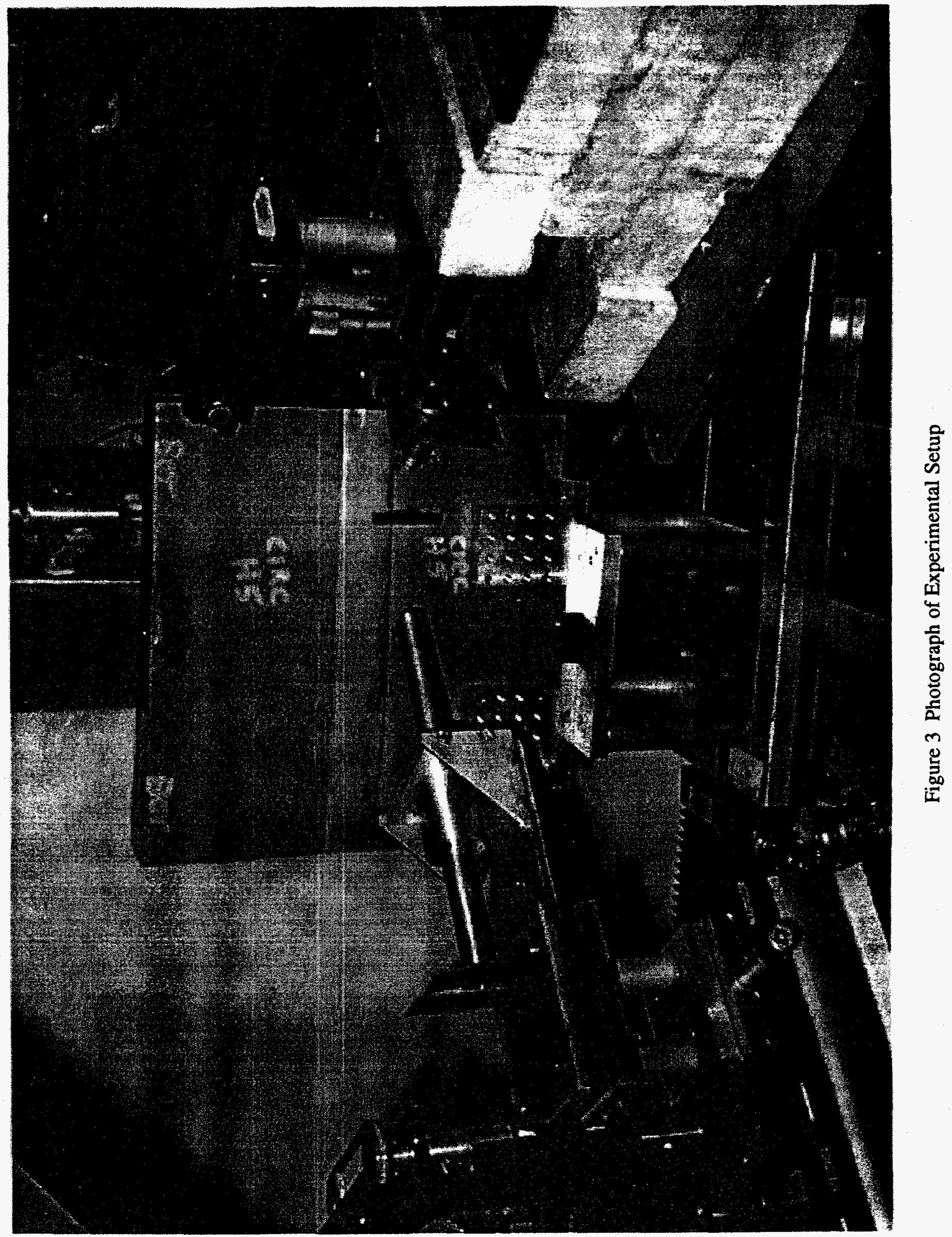




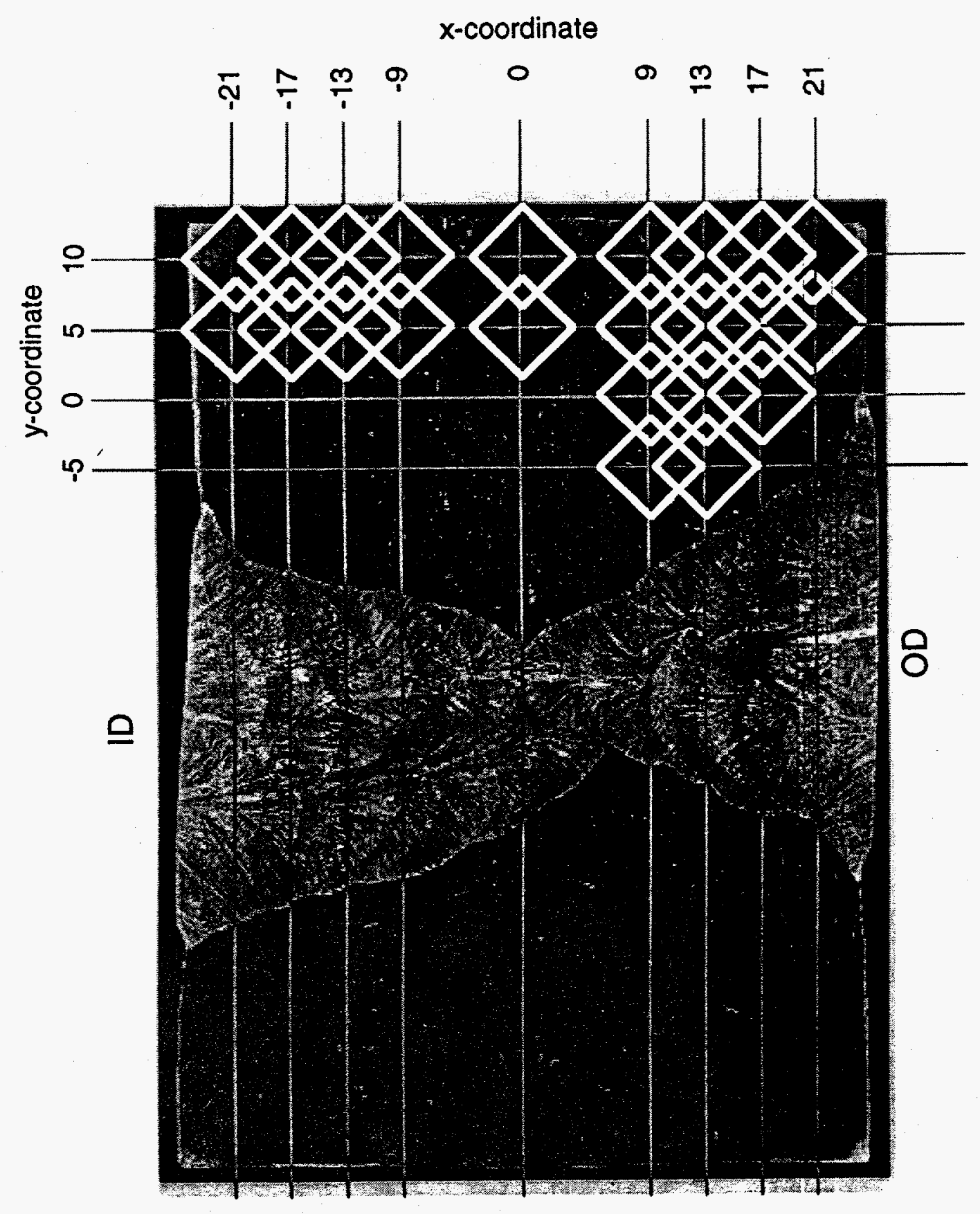

告 
Figure 5 Axial Strain

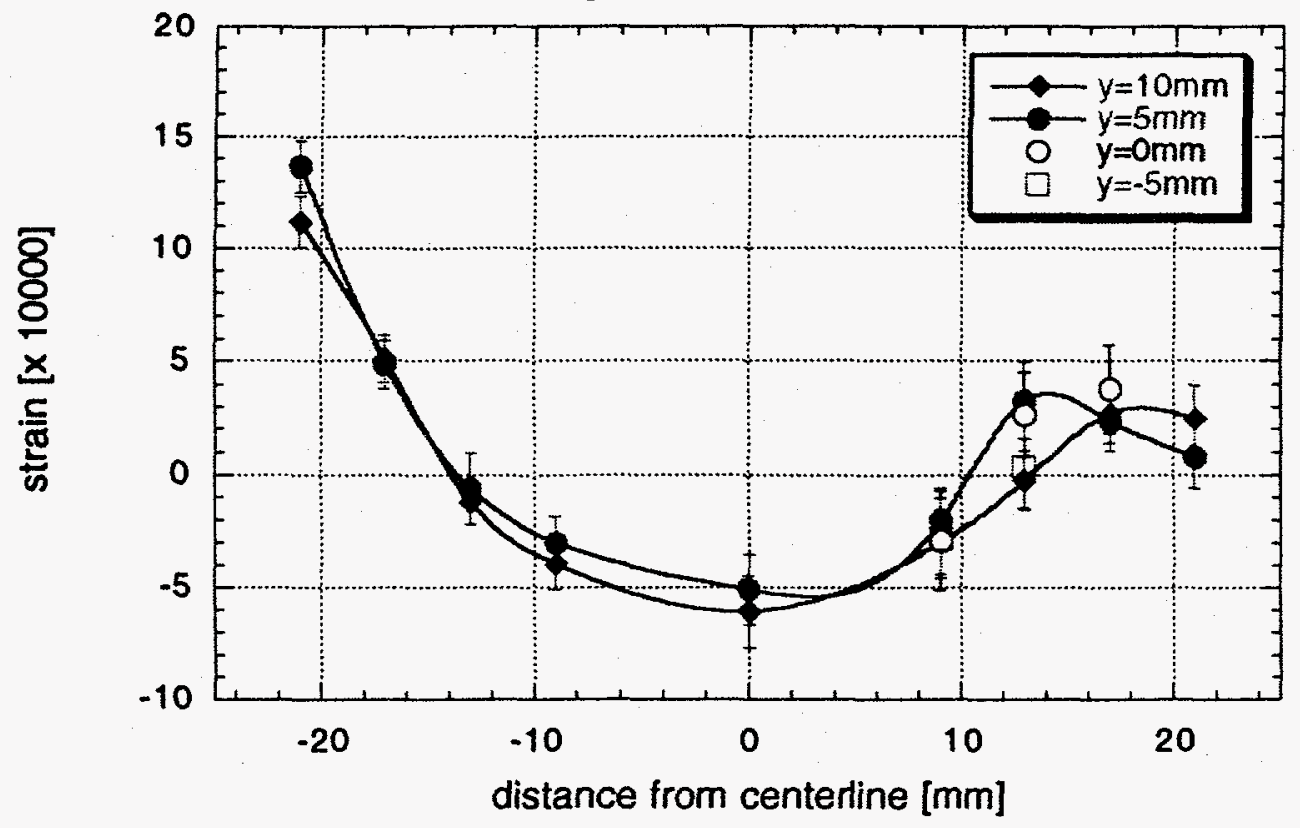

Figure 6 Hoop Strain

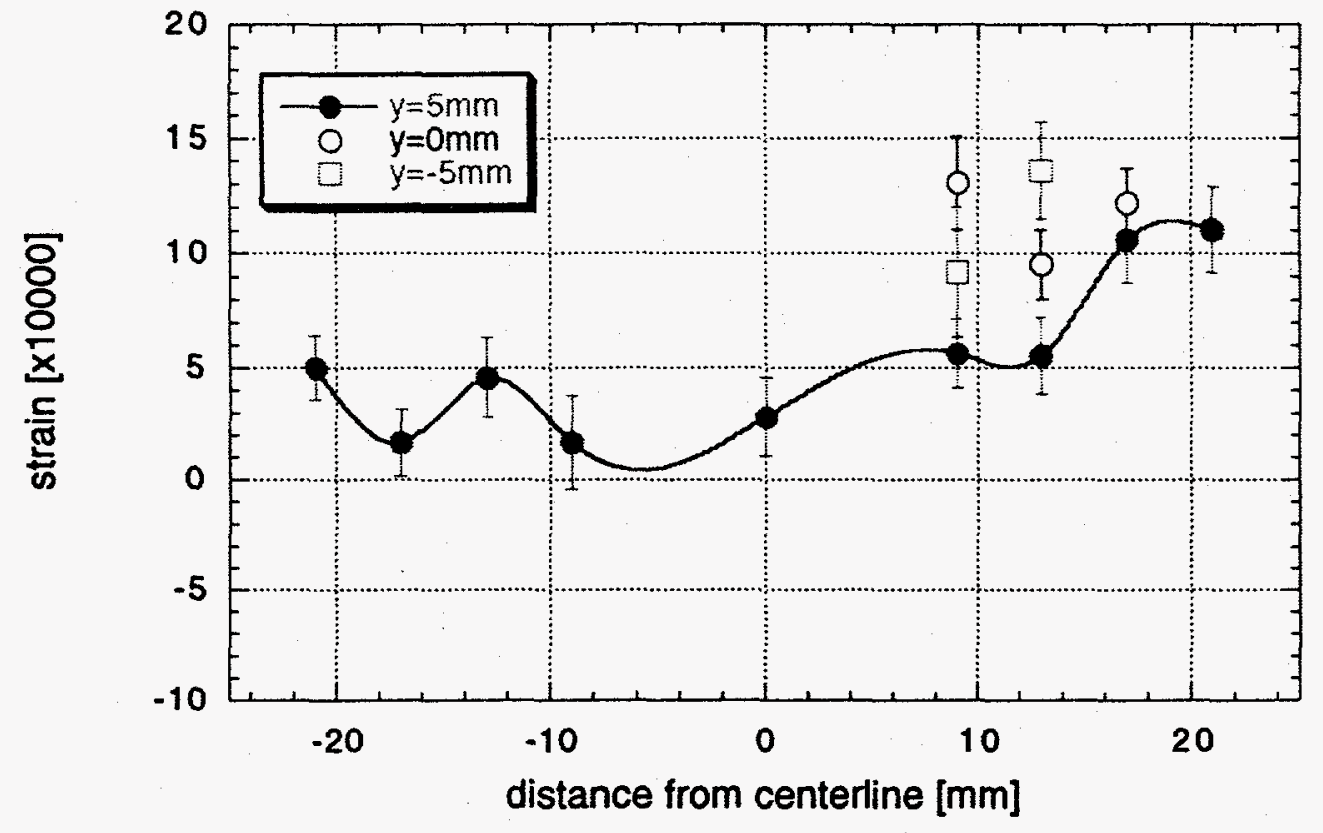


Figure 7 Radial Strain

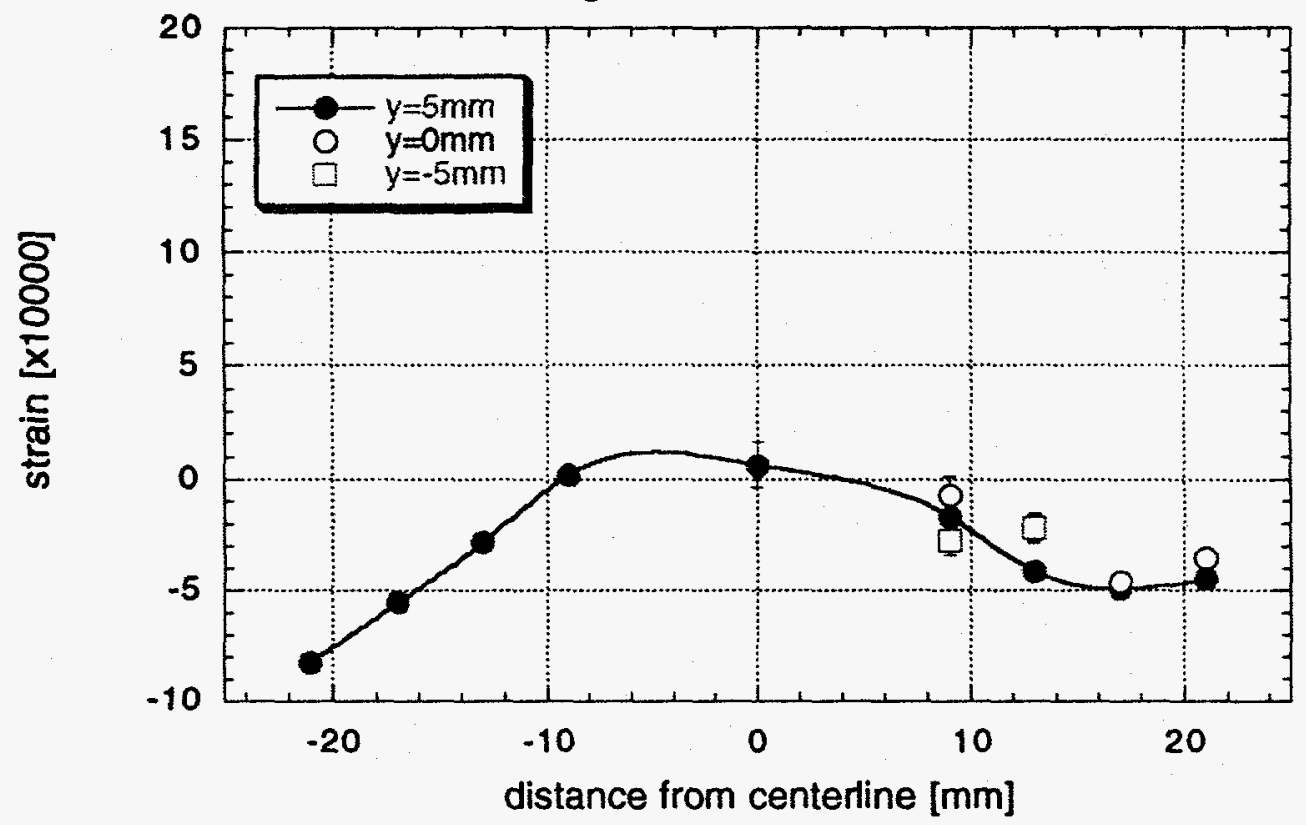

Figure 8 Axial Stress

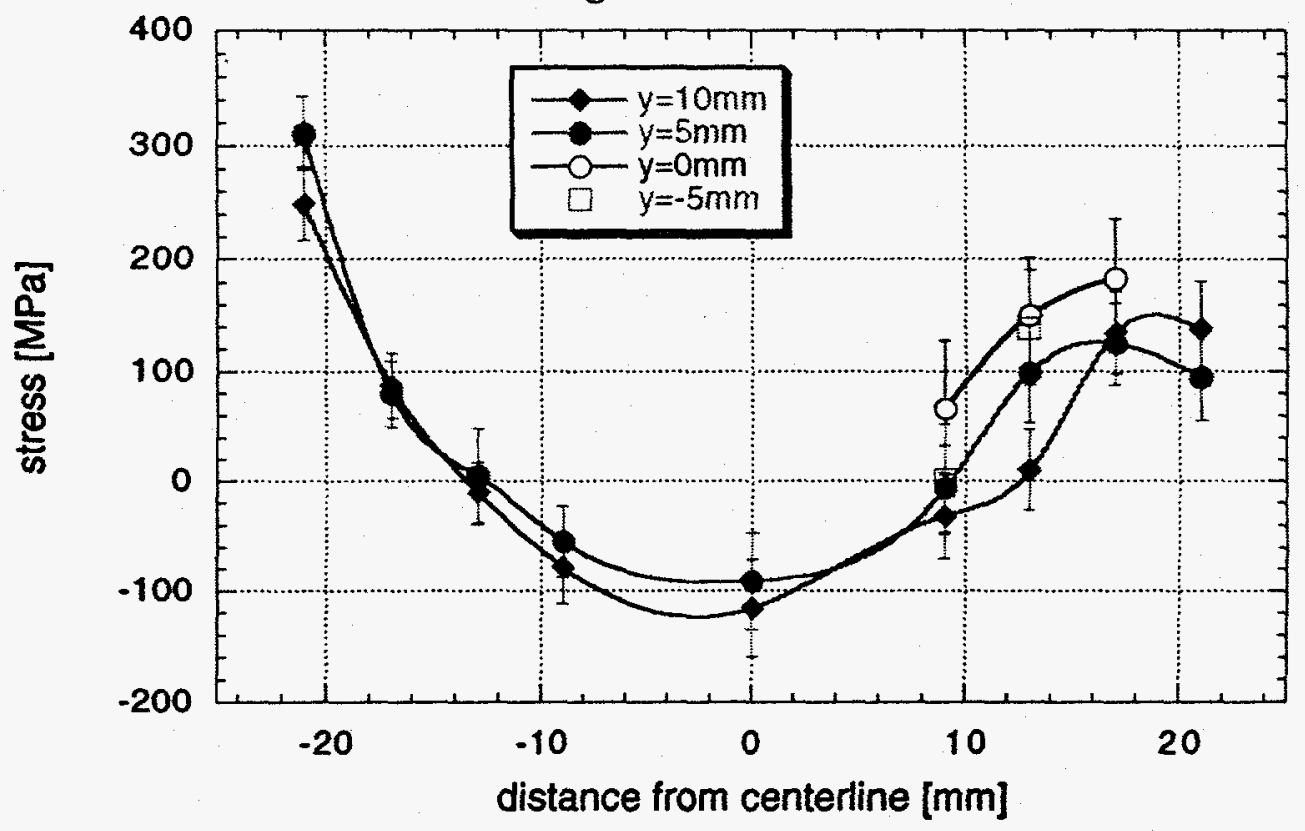


Figure 9 Hoop Stress

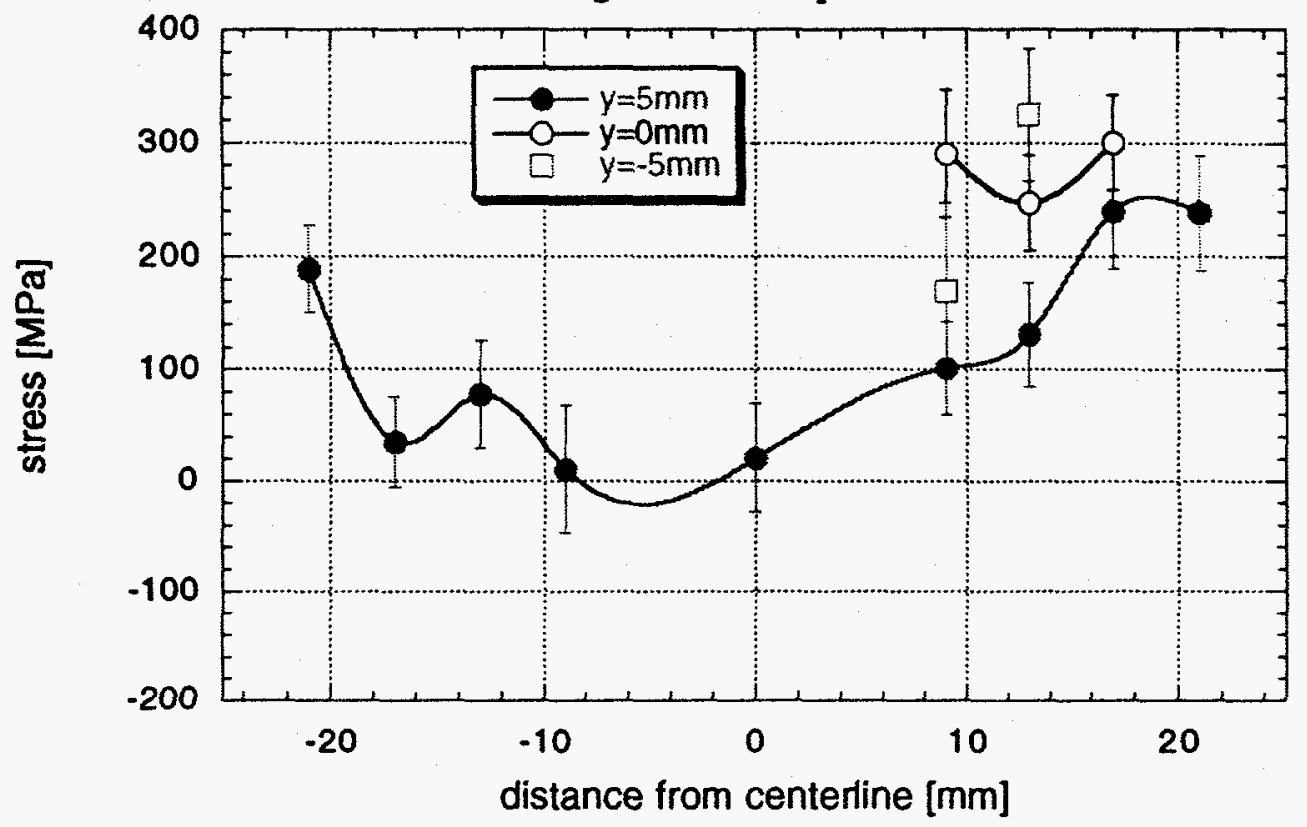

Figure 10 Radial Stress

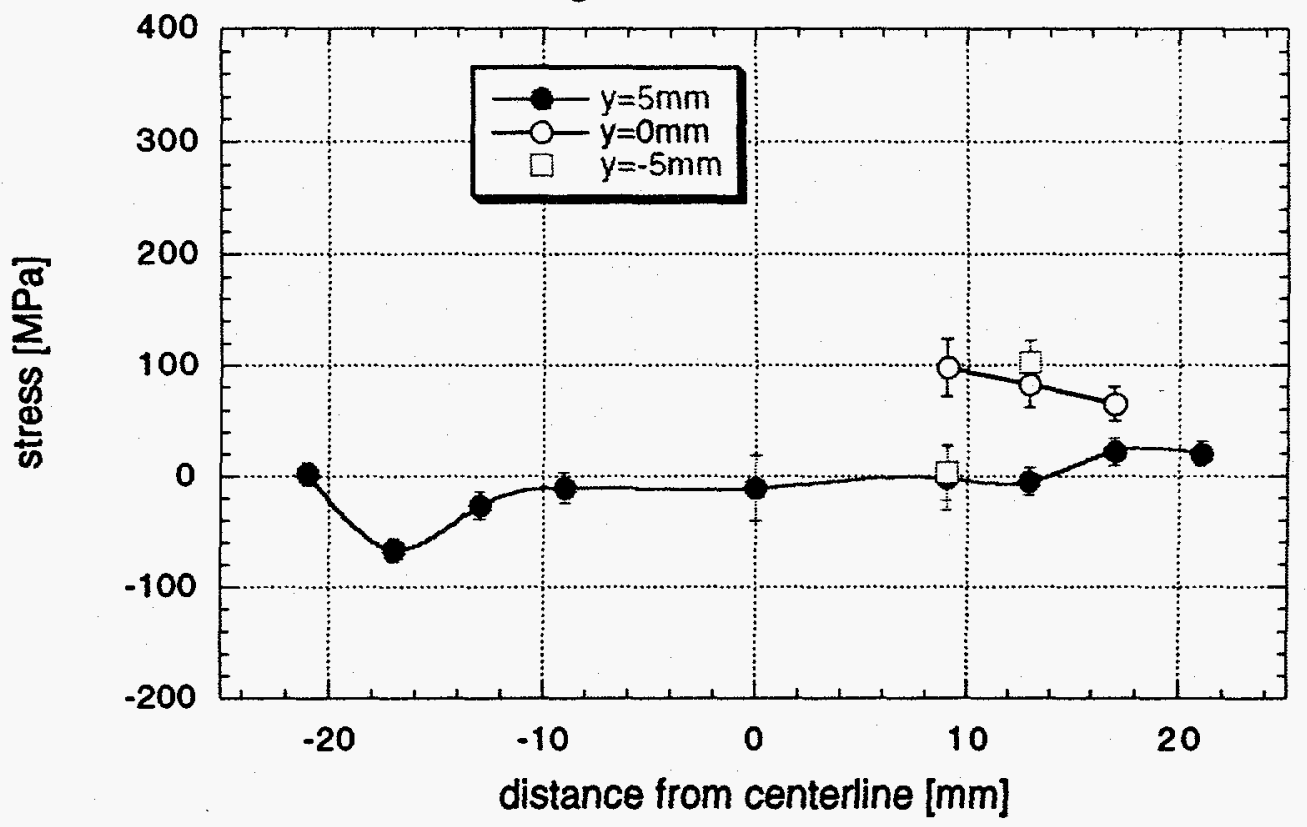

